\title{
Biochemical parameters and oxidative stress markers in Tunisian patients with periodontal disease
}

\author{
Ahmed Gharbi ${ }^{1,2^{*}}$ (D), Ali Hamila ${ }^{3}$, Adel Bouguezzi ${ }^{4}$, Azza Dandana', Salima Ferchichi ${ }^{1}$, Fatiha Chandad ${ }^{5}$, \\ Leila Guezguez ${ }^{6}$ and Abdelhedi Miled ${ }^{1}$
}

\begin{abstract}
Background: Oxidative stress is involved in many diseases including diabetes and cancer. Numbers of studies have suggested its involvement in the pathogenesis of periodontal diseases. The aim of this study was to evaluate the levels of biochemical parameters and oxidative stress markers in plasma of healthy and chronic periodontitis patients.

Methods: One hundred thirty subjects were divided into two groups; patients (mean age $=42 \pm 13.6$ y.o) and control (mean age $=44.8 \pm 12.6$ y.o). Patients and healthy subjects were free from any infection, coronary or heart disease, diabetes or liver failure. Total cholesterol, LDLc, HDLc, Triglycerides (TG), creatinine, uric acid (UA), glucose and urea levels as well as the activities of enzymatic antioxidants such as catalase, glutathione reductase (GR) and total antioxidant capacity (TAOC), were measured in plasma samples using colorimetric assays. Statistical differences between groups were determined by Student's t-test and $p \leq 0.05$ was considered as significant.

Results: Periodontitis patients exhibited significant decrease in the activities of catalase, TAOC, GR and TG, cholesterol, LDLc, glucose, HDLc, uric acid levels in plasma samples in comparison with healthy subjects. However, no statistically significant differences in the levels of creatinine and urea were observed between the two groups.

Conclusion: The reduction of plasma antioxidant activities (Catalase, TAOC, GR) may have a role in the pathogenesis of periodontal diseases. Our findings suggest a decrease in the host capacity to control the damage caused by oxidative stress. Therefore, therapeutic strategies, aiming at modulating the oxidative stress could be considered as potential tools for the prevention or treatment of periodontal diseases and their potential systemic effects on the general health.
\end{abstract}

Keywords: Periodontal disease, Oxidative stress, GR, TOAC, Antioxidant, Periodontitis

\section{Introduction}

Periodontitis is known as an inflammatory disease that affects oral health. It's the leading cause of tooth loss, secondary to periodontal pocket formation and alveolar bone resorption. In high income countries, the disease affects $10-15 \%$ of adults $[1,2]$. The pathogenesis stems from a combination of factors, involving periodontal bacteria, inflammatory immune responses, patient behavioral (life style) and concomitant medical conditions.

\footnotetext{
* Correspondence: gharbii.ahmad@gmail.com

'Biochemistry Laboratory CHU Farhat Hached, Sousse, Tunisia

${ }^{2}$ Biological and Clinical Dento-facial Approach Laboratory LR12ES10, Monastir, Tunisia

Full list of author information is available at the end of the article
}

More recently this pathology has been linked to several metabolic diseases, including diabetes and cardiovascular diseases. The association between aging and periodontitis is not conclusively proved [1, 3].

Recently, it has been suggested that the increase of inflammation accompanying periodontitis is considered as a risk factor for certain systemic diseases such as diabetes type $2[3,4]$, cardiovascular and cerebrovascular diseases $[5,6]$. On the Other hand it has been demonstrated that oxidative stress triggers the chronic state of periodontitis as evidenced by an increased levels of biomarkers for tissue damage $[7,8]$.

Chronic and aggressive periodontitis are characterized by an increased production of reactive oxygen species

(c) The Author(s). 2019 Open Access This article is distributed under the terms of the Creative Commons Attribution 4.0 International License (http://creativecommons.org/licenses/by/4.0/), which permits unrestricted use, distribution, and 
(ROS), which may be attributed to the functional activation of polymorphonuclear leucocytes (PMNLs) $[6,7]$. To date, no explanation has been provided regarding the involvement of ROS production in the progression of periodontal diseases, but its impact cannot be considered in isolation, as various antioxidant species are involved in the defense mechanisms against excess ROS activity and maintain a delicate equilibrium within the host tissues [9]. Many studies have reported that these molecules are capable of inducing the destruction of periodontal tissues and are associated with osteoclastic bone resorption, as well [8].

Its well known that inflammation is strongly associated to increased oxidative stress components in periodontal disease. Thus, an uncontrolled inflammatory response in periodontitis can serve as an intermediate variable between them [10].

The aim of this study was to evaluate the levels of biochemical parameters and oxidative stress markers in plasma of healthy and chronic periodontitis patients in a Tunisian population.

\section{Patients and methods}

\section{Study groups}

The current study included a total of one hundred thirty subjects (130), comprising 80 periodontitis patients (PG, 47 females and 33 males, aged from 20 to 60 years), and 50 periodontal healthy controls (CG, 25 females and 25 males, aged from 20 to 60 years). The recruited participants were selected among individuals who were referred to the Faculty of dental medicine (Monastir University, Tunisia) for periodontal problems or routine periodontal controls from October 2013 to April 2014. The Subjects admitted to the dental clinic for routine periodontal follow-up and the individuals without any periodontal problems were included in the control group.

All the patients involved in the study had no history of systemic condition, alcohol and tobacco consumption or any drug intake, as previously reported [11]. The participants were informed of the study, and they gave their informed consent.

\section{Clinical measurements}

Clinical and radiological diagnosis for periodontal diseases were performed according to the criteria of the American Academy of Periodontology $[12,13]$. The periodontal status of all the individuals was determined by measuring the probing pocket depth (PPD) using a periodontal probe (PCP-UNC15, Hu-friedy), the gingival bleeding index (GBI), and the plaque index (PI). The diagnosis of chronic periodontitis was made based on the following criteria: clinical attachment loss (CAL), 3 to $4 \mathrm{~mm}$, radiographic periodontal bone loss (coronal third), 15 to $33 \%$ and a PPD of $\leq 5 \mathrm{~mm}$.

\section{Collection of blood samples}

Blood samples were collected $48 \mathrm{~h}$ after the clinical measurements, in the morning and after an overnight fasting.

Venous blood was collected in plain tubes (for serum). All tubes were maintained at $4{ }^{\circ} \mathrm{C}$ for $30 \mathrm{~min}$ before centrifugation at $1500 \mathrm{xg}$ for $10 \mathrm{~min}$. Serum samples were collected, aliquoted into cryogenic vials and stored in $-20^{\circ} \mathrm{C}$.

\section{Measurement of biochemical variables}

The Levels of Cholesterol (TC), triglyceride (TG), highdensity lipoprotein cholesterol (HDLc), low-density lipoprotein cholesterol (LDLc), creatinine, uric acid, glucose and serum urea were measured using standardized enzymatic methods (Randox-Antrim, UK).

\section{Determination of the oxidative state markers}

TAOC levels of serum samples were measured using commercially available human-specific enzyme-linked immunosorbent assays (ELISA), following the instructions of the manufacturer (Cayman Chemical, Ann Arbor, MI, USA). The concentration values in serum were expressed as milli molar Trolox equivalent for TAOC.

Glutathione reductase (GR) activity was determined by measuring the rate of NADPH oxidation using a GR assay kit (Cayman Chemical, Ann Arbor, MI, USA).

The catalase (CAT) activity was determined spectrophotometrically as the rate of substrate decomposition per unit time [14].

\section{Statistical analysis}

All entered data were analysed using SPSS software (Statistical Package for the Social Sciences version 15 USA). The kolmogorov-Smirnov normality test was used to assess data distribution. Variables with a normal distribution were expressed as means \pm SD or standard error 95\% Confidence Interval and then compared using the Student's t-test for independent samples. Qualitative variables were expressed as frequencies and percentages. The Chi2 test was used to compare qualitative data. The level of significance was set at $p \leq 0.05$.

\section{Results}

\section{Clinical findings}

The mean values of clinical parameters are reported in Table 1. Mean values of PPD, GBI and PI were significantly higher in the PG compared to the CG, However, No significant difference was observed for both groups according to the gender $(p \leq 0.05)$.

\section{Biochemical parameters}

The mean concentration of plasma TG and HDlc, CT, LDLc, Levels from the PG and CG are given in Table 2. 
Table 1 Comparison of clinical periodontal parameters among the groups

\begin{tabular}{lllll}
\hline $\begin{array}{l}\text { Groups } \\
\text { Parameter }\end{array}$ & $\begin{array}{l}\text { Patients } n=80 \\
\text { Median }\end{array}$ & Controls $n=50$ & $P$ & $95 \% \mathrm{Cl}$ \\
\hline PPD (mm) & $5.3(2.5$ to 7.5$)$ & $1(0.5$ to 2$)$ & 0.05 & $4.99-0.70$ \\
GBI & $1.96(0$ to 3$)$ & $0.75(0$ to 1$)$ & 0.05 & $2.38-0.67$ \\
PI & $64.4(10$ to 100$)$ & $35(10$ to 100$)$ & 0.05 & $65.81-34.71$
\end{tabular}

Patients $n=80$; Controls $n=50$. Normally distributed data are expressed as means $\pm \mathrm{SD}$, and non normally distributed data are expressed as median (IQR [interquartile range]). PPD Probing pocket depth, GBI Gingival bleeding index $P I$ Plaque index. The difference is significant compared with the control group $(P \leq 0.05)$

The TG $(p \leq 0.05)$, LDLc $(p<0.05)$ and TC $(p<0.05)$ concentrations were significantly higher in the PG compared to the CG. The plasma HDLc concentration was statistically decreasing in the PG compared with the CG $(p<0.05)$.

The mean concentration of plasma creatinine, uric acid, glucose and urea levels from the patients and control groups are given in Table 3. The plasma glucose and uric acid levels were statistically higher among the PG compared with the CG ( $p \leq 0.05)$.

There was no statistically significant difference for the plasma creatinine and urea in the PG compared with the CG $(p>0.05)$.

The plasma mean levels of enzymatic antioxidants (catalase, GR and TAOC) in plasma among the groups are given in Table 4 . The index values showed strong statistically significant difference among the groups $(p<0.05)$. The values were significantly higher in the CG than in the PG.

\section{Discussion}

Periodontitis is an inflammatory disease of infectious nature affecting the tooth supporting tissues. The presence of periodontopathogenic bacteria in the gingival crevice is the primary etiological factor responsible for triggering periodontitis. The immune response of the host to the aggression by these periodontopathogenic

Table 2 Comparison of plasma concentrations of CT, LDLC, TG and HDLc levels among the groups

\begin{tabular}{lllll}
\hline $\begin{array}{l}\text { Groups } \\
\text { Value }\end{array}$ & $\begin{array}{l}\text { Patients } \\
\text { Values }\end{array}$ & Controls & $P$ & $95 \% \mathrm{Cl}$ \\
\hline Plasma TC $(\mathrm{mmol} / \mathrm{l})$ & $4.75 \pm 1.10$ & $4.2 \pm 0.86$ & 0.02 & $4.40-4.73$ \\
Plasma LDLc $(\mathrm{mmol} / \mathrm{l})$ & $2.3 \pm 0.72$ & $2.08 \pm 0.86$ & 0.05 & $2.30-2.57$ \\
Plasma TG $(\mathrm{mmol} / \mathrm{l})$ & $1.4 \pm 0.91$ & $1.1 \pm 0.56$ & 0.05 & $1.19-1.42$ \\
Plasma HDLc $(\mathrm{mmol} / \mathrm{l})$ & $1.3 \pm 0.41$ & $1.41 \pm 0.43$ & 0.03 & $1.14-1.28$ \\
\hline
\end{tabular}

Patients, $n=80$; Controls, $n=50$. Normally distributed data are expressed as means $\pm S D$, and non normally distributed data are expressed as median (IQR [interquartile range]). CT Cholesterol, $L D L C$ Low-density lipoprotein cholesterol, TG Triglycerides, HDLc High-density lipoprotein cholesterol. The difference is significant compared with the control group $(P \leq 0.05)$ agents determines the course of the disease to the tissue destruction or recovery.

In our study, biochemical parameters showed an increase in cholesterol, LDLc, glucose and triglyceride and a decrease for HDLc. However, no significant difference was found for creatinine and urea.

\section{Study of the lipid profile}

The mean values of total plasma cholesterol (TC), LDLc were significantly higher in patients while HDLc was significantly lower compared to controls.

These results corroborate those reported by Dhotre et al. [15] and Lösche et al. [16].

Jaramillo et al. [17] found that untreated periodontal diseases were associated with altered lipid markers related to cardiovascular disorders.

However, the study conducted by Gita et al. in 2012 showed no association between periodontal diseases and total cholesterol, LDLc, HDLc and triglycerides levels [18].

The disturbance of the lipidic metabolism could be explained by the inhibition of the lipase lipoprotein secondary to the release of pro-inflammatory cytokines, such as IL-1 $\beta$ and TNF- $\alpha$ during periodontal diseases. Furthermore, the increase of the cardiovascular disease risk might be due to the impairment of the HDLc antiatherogenic properties.

\section{Urea and creatinine}

Our results showed, as recorded by Brotto et al. [19], no significant difference in the plasma urea and creatinine levels between the two groups.

Several studies have shown a positive relationship between periodontitis and abnormally high serum creatinine associated with renal dysfunction. For instance, in 2005, Kshirsagar et al. [20] demonstrated a correlation between periodontitis and kidney failure and the results showed a significant increase in the levels of creatinine in patients compared to controls.

\section{Glucose}

In our study we have shown a significant increase in blood glucose levels in patients compared to controls.

These results are consistent with those described by Lösche et al. [16]. These observations may indicate that these patients were in a pre-diabetic condition and had uncontrolled blood glucose. In fact, poor blood sugar control is known as an established risk factor for periodontitis.

\section{Study of oxidative stress markers}

ROS are known to be involved in periodontal diseases, and their effect will be modulated in vivo by the antioxidant defense system [21]. 
Table 3 Comparison of creatinine, uric acid, glucose and urea in plasma among the groups

\begin{tabular}{lllll}
\hline Groups & Patients & Controls & $P$ & $95 \% \mathrm{Cl}$ \\
& Values & & value \\
\hline Plasma creatinine $(\mu \mathrm{mol} / \mathrm{l})$ & $64.93 \pm 15.25$ & $66.62 \pm 10.35$ & 0.13 & $63.62-67.97$ \\
Plasma Uric Acid $(\mathrm{mmol} / \mathrm{l})$ & $310.37 \pm 53.86$ & $245.82 \pm 66$ & 0.05 & $275.35-295.66$ \\
Plasma Glucose $(\mathrm{mmol} / \mathrm{l})$ & $4.8 \pm 1$ & $3.9 \pm 0.80$ & 0.05 & $4.41-4.67$ \\
Plasma Urea $(\mu \mathrm{mol} / \mathrm{l})$ & $4.60 \pm 1.36$ & $5.06 \pm 0.56$ & 0.31 & $4.40-4.89$ \\
\hline
\end{tabular}

Patients, $n=80$; Controls, $n=50$. Normally distributed data are expressed as means $\pm S D$, and non normally distributed data are expressed as median (IQR

[interquartile range]).The difference is significant compared with the control group $(P \leq 0.05)$

\section{Catalase}

Our results showed a statistically significant decrease in erythrocyte catalase activity. These results are in line with those recorded by Thomas et al. [22]. This could explain the decrease in the catalase for patients with periodontal diseases at an advanced stage.

Conversely, a study conducted by Panjamurthy et al. [3] showed that the level of catalase and other enzymatic antioxidants (SOD) were elevated in patients compared to controls.

In this regard, it is well known that the antioxidant reactions found in different pathologies depend on the severity or spread of the disease [23, 24].

\section{Uric acid}

Uric acid is an antioxidant molecule with powerful reducing free radicals [25]. In our study, a significant increase in the uric acid level was found in patients compared to controls. These results corroborate with those found by Ziebolz et al. [26] and Banu Sand et al. [27], who considered that uric acid could be used as a readily detectable mediator of inflammation in periodontitis.

However Brotto et al. [19] showed a non-significant increase of uric acid in patients compared to controls.

\section{Glutathione reductase (GR)}

Reduced glutathione is an antioxidant marker, with multiple biological functions. It prevents oxidative stress, removes hydroperoxides, detoxifies and stabilizes biological membranes. Therefore, our results are in accordance with those of Chapple et al. [9] who reported that patients having periodontal disease show a lower concentration of glutathione in their serum and gingival crevicular fluid.

\section{TOAC}

The results of our study for serum TAOC levels are in agreement with the observations of Chapple et al. [2] and Brock et al. [21]. The authors showed that plasma TAOC levels were significantly reduced in patients with chronic periodontitis $(P \leq 0.001)$ and gingivitis $(P \leq 0.001)$ when compared with age and sex matched healthy controls. The destruction can be explained by an imbalance between the production of the antioxidant and the ROS. The increased of ROS production is a result of the inflammatory infiltrate of PMNs as a host response against microbial invasion. The infiltration of PMN in numbers is likely to result in an increase in ROS levels causing oxidative stress. Thomas et al. [22] reported that the increased gingival crevicular fluid lipid peroxidation levels reflected the increased ROS damage to the periodontal tissues and lead to periodontal inflammation.

Hence, oxidative stress lies at the heart of the periodontal tissue. It results from host-microbial interactions. It can be either direct resulting from excess ROS activity/antioxidant deficiency or indirect arising from the activation of redox-sensitive transcription factors and the creation of a pro-inflammatory state.

Taking these data as well as our results into consideration, we hypothesize that periodontal disease may be a potential risk factor for the severity, progression and even the onset of cardiovascular diseases. This is due to a reduced antioxidant capacity and an increased oxidative stress and atherogenic lipoproteins [16].

Table 4 Comparison of the activities of enzymatic antioxidants (Catalase, GR and TAOC) in plasma among the groups

\begin{tabular}{|c|c|c|c|c|}
\hline \multirow{2}{*}{$\begin{array}{l}\text { Groups } \\
\text { Value }\end{array}$} & Patients & Controls & \multirow{2}{*}{$\begin{array}{l}P \\
\text { value }\end{array}$} & \multirow[t]{2}{*}{$95 \% \mathrm{Cl}$} \\
\hline & \multicolumn{2}{|l|}{ Values } & & \\
\hline Plasma catalase (ku/l) & $1.95 \pm 0.40$ & $13.38 \pm 10$ & 0.001 & $5.49-8.46$ \\
\hline Plasma GR (nmol/min/ml) & $28.55 \pm 10.79$ & $48.72 \pm 8.02$ & 0.001 & $33.91-38.72$ \\
\hline Plasma TAOC (mM trolox equivalent) & $2427 \pm 520.31$ & $4192 \pm 465$ & 0.002 & $2933.42-3279.01$ \\
\hline
\end{tabular}

Patients, $n=80$; Controls, $n=50$. Normally distributed data are expressed as means \pm SD, and non normally distributed data are expressed as median (IQR [interquartile range]). GR Glutathione reductase, TAOC Total antioxidant capacity. The difference is significant compared with the control group $(P \leq 0.05)$ 


\section{Conclusion}

- Plasma antioxidant activities (catalase, TAOC, GR) are decreased in the periodontally compromised group compared with the control group,

- Our findings suggest a decrease in the host capacity to control the damage caused by oxidative stress,

- Further studies are needed to better evaluate the role of reactive oxygen species in the pathogenesis of chronic periodontitis and their potential systemic effects on the general health.

\begin{abstract}
Abbreviations
CAL: Clinical attachment loss; CAT: Catalase; GBI: Gingival bleeding index; GR: Glutathione reductase; HDLc: High-density lipoprotein cholesterol; LDLc: Low-density lipoprotein cholesterol; MDA: Malondialdehyde; PI: Plaque index; PMNLs: Polymorphonuclear leucocytes; PPD: Periodontal probing depth; ROS: Reactive oxygen species; SOD: Superoxide dismutase; TAOC: Total antioxidant capacity; TBA: Thiobarbituric acid; TC: The Levels of Cholesterol; TG: Triglycerides; UA: Uric acid
\end{abstract}

\section{Acknowledgements}

This work was supported by the Ministry of Higher Education and Scientific Research and by the Ministry of Public Health of the Tunisian Government. We would like to thank Pr. Fatiha Chandad (Groupe de recherche en écologie buccale, Faculty of Dental Medicine, Laval University, Quebec, Canada) for her help in the realisation of the Elisa Test and Pr. Latifa Berrezouga (Faculty of Dentistry, Monastir University, Tunisia) for the final revision of the manuscript.

\section{Authors' contributions}

AG carried out the different experiments and drafted the manuscript; $A H$ and $\mathrm{AD}$ participated in the measurement of the different parameters related to the oxidant-anti-oxidant status; AB, SF, FC and LG participated in the design of the study and coordination and helped to draft the manuscript; AM participated in the different experiments, in the design of the study and the draft of the manuscript. All authors read and approved the final manuscript.

\section{Funding}

The study design, the collection, analysis, and interpretation of data and writing the manuscript were funded by the research Lab Biological and Clinical Dento-facial Approach Laboratory LR12ES10 Faculty of Dental Medicine Monastir.

\section{Availability of data and materials}

All data generated or analyzed during this study are included in this published article are available from the corresponding author on reasonable request.

\section{Ethics approval and consent to participate}

The protocol and the consent forms of the study were evaluated and approved by the Ethics Committee of the University School of Medicine in accordance with Helsinki declaration. All patients and control subjects gave their verbal consent, and accepted the collection of $5 \mathrm{ml}$ of blood. The Ethics Committee considered the verbal consent as appropriate since most patients preferred not to give a written consent. It should be specified that our intervention with patients was limited to samples' collection.

\section{Consent for publication}

Not applicable.

\section{Competing interests}

The authors declare that they have no competing interests.

\section{Author details}

'Biochemistry Laboratory CHU Farhat Hached, Sousse, Tunisia. ${ }^{2}$ Biological and Clinical Dento-facial Approach Laboratory LR12ES10, Monastir, Tunisia.

${ }^{3}$ Laboratory of Physiology, Faculty of Medicine Sousse, Sousse, Tunisia.
${ }^{4}$ Department of Oral Medicine and Surgery, School of Dental Medicine, University of Monastir, Sousse, Tunisia. ${ }^{5}$ Oral Ecology Research Group, Faculty of Dental Medicine, Laval University, Sousse, Tunisia. ${ }^{6}$ Department of Periodontology, School of Dental Medicine, University of Monastir, Sousse, Tunisia.

Received: 1 April 2018 Accepted: 17 September 2019

Published online: 22 October 2019

\section{References}

1. Fox $\mathrm{CH}$. New considerations in the prevalence of periodontal disease. Curr Opin Dent. 1992;2:5-11.

2. Chapple IL, Milward MR, Dietrich T. The prevalence of inflammatory periodontitis is negatively associated with serum antioxidant concentrations. J Nutr. 2007;137(3):657-64

3. Panjamurthy K, Manoharan S, Ramachandran CR. Lipid peroxidation and antioxidant status in patients with periodontitis. Cell Mol Biol Lett. 2005; 10(2):255-64.

4. Kantarci A, Oyaizu K, Van Dyke TE. Neutrophil-mediated tissue injury in periodontal disease pathogenesis: findings from localized aggressive periodontitis. J Periodontol. 2003;74(1):66-75.

5. Kowashi Y, Jaccard F, Cimasoni G. Sulcular polymorphonuclear leucocytes and gingival exudate during experimental gingivitis in man. J Periodontal Res. 1980;15(2):151-8.

6. Fredriksson M, Gustafsson A, Asman B, Bergstrom K. Hyper-reactive peripheral neutrophils in adult periodontitis: generation of chemiluminescence and intracellular hydrogen peroxide after in vitro priming and FcgammaR-stimulation. J Clin Periodontol. 1998;25(5):394-8.

7. Gustafsson A, Asman B. Increased release of free oxygen radicals from peripheral neutrophils in adult periodontitis after fc delta-receptor stimulation. J Clin Periodontol. 1996;23(1):38-44.

8. Key LL Jr, Wolf WC, Gundberg CM, Ries WL. Superoxide and bone resorption. Bone. 1994;15(4):431-6.

9. Chapple IL, Brock G, Eftimiadi C, Matthews JB. Glutathione in gingival crevicular fluid and its relation to local antioxidant capacity in periodontal health and disease. Mol Pathol. 2002;55(6):367-73.

10. Sculley DV, Langley-Evans SC. Periodontal disease is associated with lower antioxidant capacity in whole saliva and evidence of increased protein oxidation. Clin Sci (Lond). 2003;105(2):167-72.

11. Baltacıoğlu E, Yuva P, Aydın G, Alver A, Kahraman C, Karabulut E, Akalın FA. Lipid peroxidation levels and total oxidant/antioxidant status in serum and saliva from patients with chronic and aggressive periodontitis. Oxidative stress index: a new biomarker for periodontal disease? J Periodontol. 2014;85(10):1432-41.

12. Jack G, Caton, Jr. 1999 International Workshop for a Classification of Periodontal Diseases and Conditions. Papers. Oak Brook, Illinois, October 30November 2, 1999. Ann Periodontol. 1999;4(1):i, 1-112.

13. Tonetti MS, Greenwell H, Kornman KS. Staging and grading of periodontitis: framework and proposal of a new classification and case definition. J Periodontol. 2018;89(Suppl 1):S159-72.

14. Goth L. A simple method for determination of serum catalase activity and revision of reference range. Clin Chim Acta. 1991;196(2-3):143-51.

15. Dhotre PS, Suryakar AN, Bhogade RB. Oxidative stress in periodontist: a critical link to cardiovascular disease. Biomedical Res. 2011;22(2):178-82.

16. Losche W, Karapetow F, Pohl A, Pohl C, Kocher T. Plasma lipid and blood glucose levels in patients with destructive periodontal disease. I Clin Periodontol. 2000;27(8):537-41.

17. Jaramillo A, Lafaurie Gl, Millan LV, Ardila CM, Duque A, Novoa C, Lopez D, Contreras A. Association between periodontal disease and plasma levels of cholesterol and triglycerides. Colomb Med (Cali). 2013;44(2):80-6.

18. Gita B, Sajja C, Padmanabhan P. Are lipid profiles true surrogate biomarkers of coronary heart disease in periodontitis patients?: a case-control study in a south Indian population. J Indian Soc Periodontol. 2012;16(1):32-6.

19. Brotto RS, Vendramini RC, Brunetti IL, Marcantonio RA, Ramos AP, Pepato MT. Lack of correlation between periodontitis and renal dysfunction in systemically healthy patients. Eur J Dent. 2011;5(1):8-18.

20. Kshirsagar AV, Moss KL, Elter JR, Beck JD, Offenbacher S, Falk RJ. Periodontal disease is associated with renal insufficiency in the atherosclerosis risk in communities (ARIC) study. Am J Kidney Dis. 2005;45(4):650-7.

21. Brock GR, Butterworth CJ, Matthews JB, Chapple IL. Local and systemic total antioxidant capacity in periodontitis and health. J Clin Periodontol. 2004;31(7):515-21. 
22. Thomas B, Madani SM, Prasad BR, Kumari S. Comparative evaluation of serum antioxidant levels in periodontally diseased patients: an interventional study. Contemp Clin Dent. 2014;5(3):340-4.

23. Halliwell B, Gutteridge JMC. Free radicals in biology and medicine. 4th ed. Oxford: Clarendon Press; 2006.

24. Borges I Jr, Moreira EA, Filho DW, de Oliveira TB, da Silva MB, Frode TS, Proinflammatory and oxidative stress markers in patients with periodontal disease. Mediat Inflamm. 2007;2007:45794.

25. Lobo V, Patil A, Phatak A, Chandra N. Free radicals, antioxidants and functional foods: impact on human health. Pharmacogn Rev. 2010;4(8):118-26.

26. Ziebolz D, Jager GC, Hornecker E, Mausberg RF. Periodontal findings and blood analysis of blood donors: a pilot study. J Contemp Dent Pract. 2007; 8(5):43-50.

27. Banu S, Jabir NR, Mohan R, Manjunath NC, Kamal MA, Kumar KR, Zaidi SK, Khan MS, Tabrez S. Correlation of toll-like receptor 4, interleukin-18, transaminases, and uric acid in patients with chronic periodontitis and healthy adults. J Periodontol. 2015;86(3):431-9.

\section{Publisher's Note}

Springer Nature remains neutral with regard to jurisdictional claims in published maps and institutional affiliations.

Ready to submit your research? Choose BMC and benefit from:

- fast, convenient online submission

- thorough peer review by experienced researchers in your field

- rapid publication on acceptance

- support for research data, including large and complex data types

- gold Open Access which fosters wider collaboration and increased citations

- maximum visibility for your research: over $100 \mathrm{M}$ website views per year

At BMC, research is always in progress.

Learn more biomedcentral.com/submissions 